\title{
Inducing ovulation early postpartum influences uterine health and fertility in dairy cows
}

\author{
J. H. J. Bittar, ${ }^{*}$ P. J. Pinedo, ${ }^{* 1}$ C. A. Risco, ${ }^{*}$ J. E. P. Santos,† W. W. Thatcher, † K. E. Hencken, ${ }^{*}$ S. Croyle, ${ }^{*}$ \\ M. Gobikrushanth, ${ }^{2}$ C. C. Barbosa, $\ddagger$ A. Vieira-Neto, $\S$ and K. N. Galvão*\# \\ *Department of Large Animal Clinical Sciences, College of Veterinary Medicine, and \\ †Department of Animal Sciences, College of Agricultural and Life Sciences, University of Florida, Gainesville 32610 \\ $\ddagger$ Faculdade de Medicina Veterinária e Zootecnia, Universidade Estadual Paulista Júlio de Mesquita Filho, Botucatu, SP, Brazil 88520 \\ §Departamento de Medicina Veterinária, Centro de Ciências Agroveterinárias, Universidade do Estado de Santa Catarina, Lages, SC, Brazil \\ 18618 \\ \#D. H. Barron Reproductive and Perinatal Biology Research Program, University of Florida, Gainesville 32610
}

\section{ABSTRACT}

The objective of the current study was to evaluate the effect of $\mathrm{GnRH}$ early postpartum on induction of ovulation, uterine health, and fertility in dairy cows. Holstein cows without a corpus luteum (CL) at $17 \pm 3$ DIM were assigned randomly to receive i.m. GnRH (n $=245)$ at $17 \pm 3$ and $20 \pm 3 \mathrm{DIM}$ or remain as controls $(\mathrm{n}=245)$. Ovaries were scanned by ultrasonography twice weekly totaling 4 examinations. Ovulation was characterized by the appearance of a CL $\geq 20 \mathrm{~mm}$ at any ultrasound or CL $<20 \mathrm{~mm}$ in 2 consecutive examinations. Clinical and cytological endometritis were diagnosed at 35 DIM. Compared with control, GnRH increased ovulation up to $3.5 \mathrm{~d}$ after the last treatment (78.7 vs. $45.0 \%)$ and did not affect the prevalence of clinical endometritis (23.9 vs. $18.6 \%$ ) or cytological endometritis (30.9 vs. $32.8 \%$ ). Prevalence of clinical endometritis increased in cows that had calving problems (32.6 vs. $15.9 \%)$ and metritis (40.6 vs. $15.8 \%$ ). Metritis increased prevalence of cytological endometritis (50.7 vs. $23.5 \%)$. Treatment with GnRH did not affect pregnancy per artificial insemination at 32 (37.6 vs. $38.6 \%)$ or $74 \mathrm{~d}$ after artificial insemination (35.0 vs. $31.5 \%$ ), but reduced pregnancy loss (6.8 vs. $18.1 \%$ ). No overall effect of GnRH treatment on hazard of pregnancy was observed; however, an interaction between GnRH treatment and ovulation showed that GnRH-treated cows that ovulated had increased hazard of pregnancy by 300 DIM compared with GnRH-treated and control cows that did not ovulate (hazard ratio $=2.0$ and 1.3 , respectively), but similar to control cows that ovulated

Received September 27, 2013.

Accepted February 24, 2014.

${ }^{1}$ Current address: Texas A\&M AgriLife Research Center, Amarillo, TX 79106.

${ }^{2}$ Current address: Department of Agricultural, Food and Nutritional Science, University of Alberta, Edmonton, AB TG6 2P5, Canada.

${ }^{3}$ Corresponding author: galvaok@ufl.edu (hazard ratio $=1.1)$. Gonadotropin-releasing hormone early postpartum induced ovulation without affecting uterine health, but failed to improve pregnancy per artificial insemination or time to pregnancy, although it reduced pregnancy loss.

Key words: dairy cow, ovulation postpartum, GnRH, uterine health, fertility

\section{INTRODUCTION}

It is well established that early cyclicity results in increased pregnancy per artificial insemination (PAI) and decreased time to pregnancy (Thatcher and Wilcox 1973; Darwash et al. 1997; Galvão et al., 2010), which is expected to increase profitability for the dairy enterprise (De Vries, 2006). Treatment with GnRH has long been used to induce ovulation in early postpartum dairy cows (Britt et al., 1974). Earlier studies showed an improvement in ovulation risk from 20 to $28 \%$ to 75 to $90 \%$ when $\mathrm{GnRH}$ was administered between 10 and 14 DIM (Britt et al., 1974; Benmrad and Stevenson, 1986). Effects of $\mathrm{GnRH}$ administration early postpartum on fertility, however, have not been consistent. Etherington et al. (1984) and Padula and Macmillan (2002) reported detrimental effects on reproductive performance because cows receiving GnRH at 15 DIM had increased frequency of pyometra and increased time to first estrus and to the first AI. Administration of GnRH between 18 and 25 DIM to cows with reproductive disorders (retained placenta, ovarian cysts, prolonged anestrus, and purulent uterine discharge) resulted in increased time to pregnancy (Stevenson and Call, 1988). Others failed to show an improvement in reproductive performance when GnRH was administered at 13 or 14 DIM (Foote and Riek, 1999) or between 26 and 34 DIM (Cavestany and Foote, 1985) in healthy cows. Nonetheless, others have reported increased PAI and reduced time to pregnancy when $\mathrm{GnRH}$ was administered between 10 and 15 DIM (Nash et al., 1980; Benmrad and Stevenson, 1986) or approximately 29 DIM (Jeong et al., 2013). 
Reduction of culling because of reproductive failure also has been achieved with GnRH administration between 8 and 23 DIM (Britt et al., 1977).

If early administration of GnRH leads to greater incidence of pyometras, this negative effect may be counteracted by administration of $\mathrm{PGF}_{2 \alpha}$, which is commonly used in most dairy herds (Caraviello et al., 2006). None of the previous studies used synchronization programs such as Presynch-Ovsynch as part of their reproductive management. Furthermore, apart from incidence of pyometra, other more prevalent uterine diseases, such as clinical endometritis and cytological endometritis (Dubuc et al., 2010), have not been thoroughly characterized; therefore justifying further investigation in this field. Our study hypothesis was that the administration of GnRH early postpartum in cows without a corpus luteum $(\mathbf{C L})$ would induce ovulation without detrimental effects on uterine health, and it would induce resumption of cyclicity in anovular cows, which is expected to increase fertility. The main objective of the current study was to evaluate the effects of administration of GnRH at $17 \pm 3$ and $20 \pm 3$ DIM in Holstein dairy cows without a CL on induction of ovulation, uterine health, and reproductive outcomes.

\section{MATERIALS AND METHODS}

\section{Cows, Housing, and Feeding}

A randomized clinical experiment was conducted on 2 freestall dairy farms located in North Central Florida from December 2010 through August 2012. All animal procedures were approved by the University of Florida Institutional Animal Care and Use Committee.

Dairy 1, the dairy unit from the University of Florida, milked approximately 500 Holstein cows twice daily with a rolling herd average of approximately $10,000 \mathrm{~kg} /$ cow. The freestall beds and walking alleys were cleaned twice daily. Twice weekly, clean and dry sand was added on the top of the freestall beds. Fans with misters and sprinklers over the feed line were present in the barns. Dairy 2 was a privately owned dairy, property of North Florida Holsteins, milking thrice daily approximately 4,800 Holstein cows with a rolling herd average of approximately $10,500 \mathrm{~kg} /$ cow. In Dairy 2, cows were housed in tunnel-ventilated freestall barns, which were cleaned thrice daily and sand bedded twice weekly. In both dairies cows were fed twice daily a TMR to meet or exceed the requirements of a second lactation Holstein cow weighing $680 \mathrm{~kg}$ of $\mathrm{BW}$ and producing $45 \mathrm{~kg}$ of $3.5 \% \mathrm{FCM} / \mathrm{d}$. Fresh water was available ad libitum. In both dairies, primiparous and multiparous cows were housed separately. Cows were vaccinated and treated for common diseases according to standard operating procedures developed with participation of the veterinarians from University of Florida, College of Veterinary Medicine, Food Animal Reproduction and Medicine Service.

\section{Study Groups, BCS, and UItrasonography of the Ovaries}

Once weekly, on Tuesday mornings, a cohort of lactating cows at $17 \pm 3$ DIM was enrolled in the study for 65 consecutive weeks in dairy 1 and for 16 consecutive weeks in dairy 2. Ovaries in 637 cows were examined initially by ultrasonography (US) at $17 \pm 3$ DIM and $23.4 \%$ were found to have a CL $(\mathrm{n}=147)$; therefore, they were not enrolled in the experiment. Nevertheless, these cows with a CL were used in some analyses. The remaining 490 cows without a CL were blocked by parity and allocated randomly to 2 treatments. The first $(\mathrm{n}=245)$ was an i.m. injection of $100 \mu \mathrm{g}$ GnRH (Gonadorelin Hydrochloride, Factrel, Zoetis Inc., Florham Park, NJ) at $17 \pm 3$ DIM (GnRH-1) and again $3.5 \mathrm{~d}$ later (Friday afternoon), at $20 \pm 3$ DIM (GnRH-2). The second treatment was a control $(\mathrm{n}=245)$ with no GnRH treatment. Figure 1 shows the schematic diagram of study activities.

Body condition was scored based on a 5 -point scoring system (Ferguson et al., 1994) at enrollment. Ovarian US was performed twice weekly (Tuesday mornings and Friday afternoons) using a portable US scanner (EasiScan, BCF Technology, Livingston, UK) with a 7.5$\mathrm{MHz}$ linear transducer; scanning began at $17 \pm 3 \mathrm{DIM}$ and continued until ovulation was detected or the cow began an ovulation synchronization protocol in dairy 1 . In dairy 2, ultrasonography also was done twice weekly (Tuesday mornings and Friday afternoons) for $2 \mathrm{wk}$ (up to $28 \pm 3$ DIM). Size of follicles and CL were measured and recorded at each US. Ovulation to GnRH-1 was determined by appearance of a CL at the subsequent US at $20 \pm 3$ DIM or the disappearance of a follicle $\geq 12 \mathrm{~mm}$ present in the US at $17 \pm 3$ DIM and the appearance of a CL at $24 \pm 3$ DIM. After excluding cows that had already ovulated to GnRH-1 ( $\mathrm{n}=157)$, ovulation to GnRH-2 was determined by the appearance of a CL at $24 \pm 3$ DIM or by the disappearance of a follicle $\geq 12 \mathrm{~mm}$ present in the US at $20 \pm 3 \mathrm{DIM}$ and the appearance of a CL in the US at $28 \pm 3$ DIM. Therefore, overall ovulation to GnRH-1 or GnRH-2 was considered in cows that had ovulated by $24 \pm 3$ DIM and had a CL formed by $28 \pm 3$ DIM.

\section{Uterine Health}

Clinical endometritis was diagnosed in both dairies at 35 DIM. Clinical endometritis was determined using 


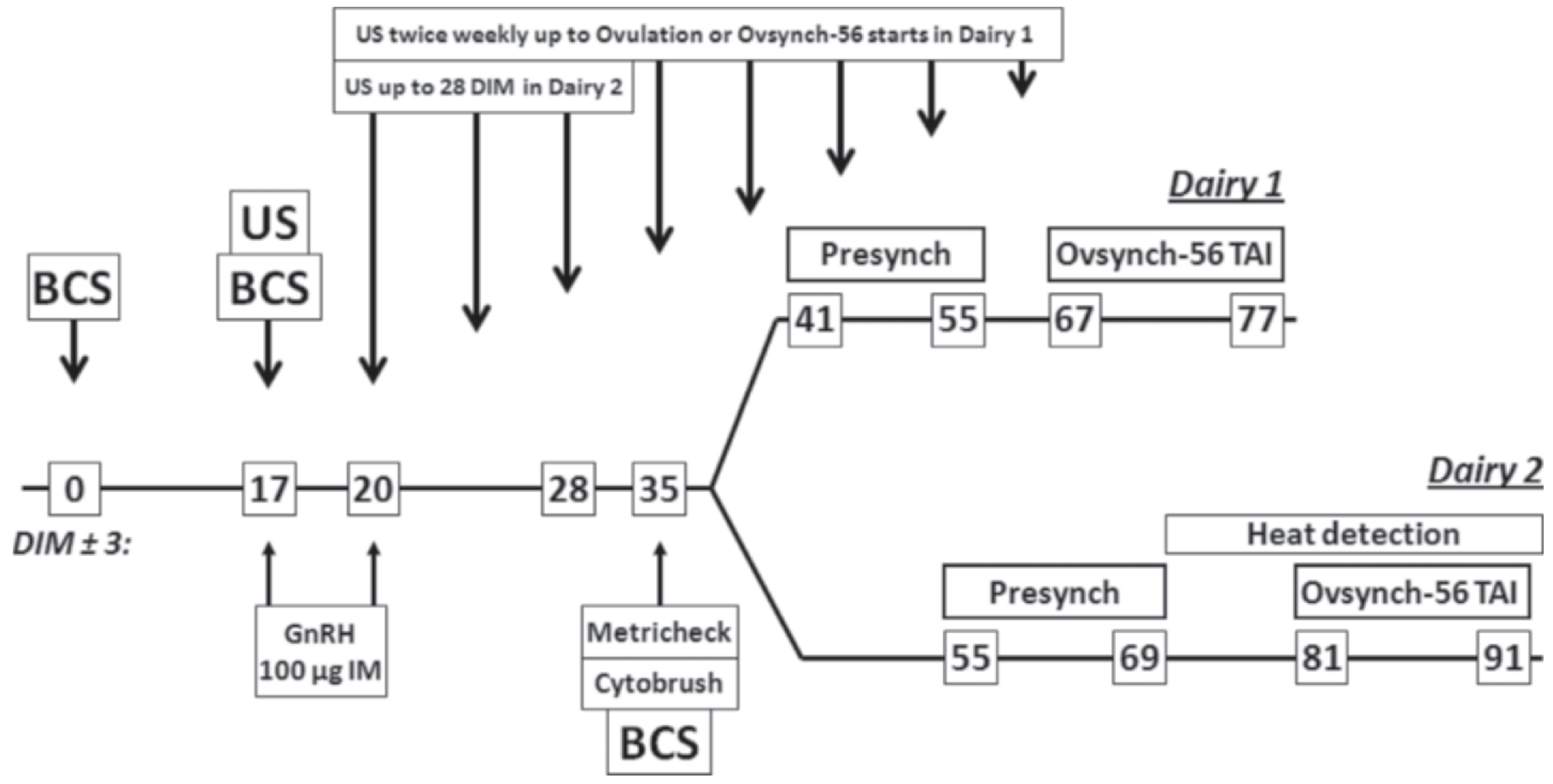

Figure 1. Schematic diagram of study activities. Weekly a cohort of cows without a corpus luteum at $17 \pm 3$ DIM was blocked by parity and assigned randomly to GnRH group (100 $\mu \mathrm{g}$ i.m. of Factrel $50 \mu \mathrm{g} / \mathrm{mL}$; Zoetis Inc., Florham Park, NJ) or remain as control (no GnRH injection). US = ultrasonography; Metricheck = evaluation of the vaginal discharge using Metricheck device (Simcro Tech Ltd. Hamilton, New Zealand); Cytobrush = uterine cytology; Presynch $=\mathrm{PGF}_{2 \alpha}$ injection $14 \mathrm{~d}$ apart; Ovsynch-56 TAI $=\mathrm{GnRH}, 7 \mathrm{~d}$ later PGF $2 \alpha, 56$ h later GnRH, 16 to 20 h later TAI; TAI = timed artificial insemination.

a Metricheck device (Simcro Tech Ltd. Hamilton, New Zealand). After cleaning of the vulva, the Metricheck device, a 50-cm long stainless steel rod with a silicon cup in one end ( $4 \mathrm{~cm}$ in diameter) was inserted into the vagina until the tip reached the fornix of the vagina. The device was then retracted. Material contained in the cup was assessed visually and classified using a scale from 0 to $3(0=$ clear or translucent mucus; $1=$ mucus containing flecks of pus; $2=$ discharge containing $<50 \%$ pus; $3=$ discharge containing $>50 \%$ pus). Scores $\geq 2$ were considered positive for clinical endometritis (Sheldon et al., 2006).

Cytological endometritis was diagnosed only in dairy 1 at 35 DIM. After cleaning and disinfecting the external vulva with alcohol (70\%), a Cytobrush Plus Cell collector (CooperSurgical Inc., Trumbull, CT) attached to a stainless steel modified AI pipette and protected by a plastic sheath protector (Continental Plastic Corp., Delavan, WI) was carefully introduced in the vagina; the pipette was exposed before entering the cervix and was maneuvered through the cervix into the body of the uterus. Once the pipette was in the uterus, the brush was exposed and pressed against the endometrium while being rotated 3 times. The brush was retrieved into the stainless steel AI gun and removed from the cow. The brush was then disconnected and smeared onto a glass slide and left to air dry. Smeared slides were then stained using a modified Wright-Giemsa stain (Diff-Quick; Camco Stain Pak 702, Cambridge Diagnostic Products Inc., Fort Lauderdale, FL) and left at room temperature to dry. A total of 200 cells per slide were counted, including all leukocyte types and epithelial cells, but excluding erythrocytes. The investigator reading the slides was blind to treatments. The proportion of polymorphonuclear neutrophil cells was determined and cytological endometritis considered with $\geq 10 \%$ of polymorphonuclear neutrophil cells, as previously described (Sheldon et al., 2006).

\section{Reproductive Management}

Cows were managed under the respective dairies' reproductive management (Figure 1). In dairy 1, estrous cycles were presynchronized with 2 injections of $\mathrm{PGF}_{2 \alpha} 14 \mathrm{~d}$ apart (Presynch) at 41 and $55 \pm 3$ DIM, followed $12 \mathrm{~d}$ later $(67 \pm 3 \mathrm{DIM})$ by Ovsynch-56 timed AI (TAI) protocol (GnRH, 7 d later $\mathrm{PGF}_{2 \alpha}, 56 \mathrm{~h}$ later GnRH, followed by AI 16 to $20 \mathrm{~h}$ later). Pregnancy diagnosis was performed by transrectal US $32 \mathrm{~d}$ after AI (i.e., pregnancy was characterized by the presence of an amniotic vesicle containing an embryo with a heartbeat). Confirmation of pregnancy was performed at 74 
d after AI by uterine palpation per rectum. Estrous cycles were resynchronized, using the Ovsynch-56 TAI program, starting on the same day when cows were diagnosed not pregnant. No detection of estrus was performed in dairy 1.

Dairy 2 had distinct reproductive protocols based on parity. Estrous cycles were presynchronized in first and second lactation cows, with 2 injections of $\mathrm{PGF}_{2 \alpha} 14 \mathrm{~d}$ apart at 50 and $64 \pm 3 \mathrm{DIM}$, followed $12 \mathrm{~d}$ later $(76$ \pm 3 DIM) by Ovsynch-56 TAI protocol. Cows in their third or greater lactation were presynchronized with 2 injections of $\mathrm{PGF}_{2 \alpha} 14 \mathrm{~d}$ apart at 55 and $69 \pm 3$ DIM, followed $12 \mathrm{~d}$ later ( $81 \pm 3 \mathrm{DIM})$ by Ovsynch- 56 TAI protocol. Nonetheless, cows were AI if detected in estrus after the second $\mathrm{PGF}_{2 \alpha}$ of the presynchronization. Pregnancy diagnosis was performed at 39 $\pm 3 \mathrm{~d}$ after $\mathrm{AI}$ and confirmed at $84 \pm 3 \mathrm{~d}$ after $\mathrm{AI}$ by uterine palpation per rectum. Estrous cycles were resynchronized, using the Ovsynch-56 TAI program, starting on the same day when cows were diagnosed not pregnant. Estrus detection was performed daily, and cows detected in estrus were considered nonpregnant and were immediately AI. Periparturient diseases, such as abortion, stillbirth, dystocia, clinical hypocalcemia, retained placenta, metritis (reddish, fetid fluid vaginal discharge within 14 DIM), and ketosis (ketones body detected before study enrollment), were diagnosed by the farm personnel, recorded on the farm management software, and later retrieved.

\section{Sample Size and Statistics}

A sample size of 225 cows per treatment was calculated (Minitab Inc., State College, PA) for $\alpha=0.05$ and $\beta=0.2$, to detect differences in PAI of $8 \%$ when PAI varies from 32 to $40 \%$. Ten cows ( 5 from each treatment) were excluded from the study because they were sold, died, or became recumbent before $28 \pm 3$ DIM. Therefore, ovulation could not be confirmed or cows did not receive their treatment as assigned. Hence, 480 cows (240 per treatment) were included in the analyses of ovulation after $\mathrm{GnRH}$ treatment and time to pregnancy up to $300 \mathrm{DIM}$. In the analysis of time to ovulation, all 255 cows from dairy 1 were used. In the analysis of cytological endometritis, only 245 cows from dairy 1 had available data (123 GnRH-treated and 122 controls). In the analysis of clinical endometritis, 45 cows had missing data; therefore, 435 cows were used (217 GnRH-treated and 215 controls). In the analysis of PAI at the first pregnancy diagnosis (PD1) and at the second pregnancy diagnosis (PD2), 21 cows were never inseminated; therefore, 459 cows were used (231 GnRH-treated and 228 controls).
Binary outcomes, such as ovulation after GnRH treatment, prevalence of clinical and cytological endometritis, PAI to the first service, and pregnancy loss from PD1 to PD2, were analyzed by logistic regression using the LOGISTIC procedure of SAS version 9.3 (SAS Institute Inc., Cary, NC) and backward elimination was performed by removing explanatory variables from the model with $P>0.05$ according to Wald-statistics criterion. Explanatory variables included in all the models were treatment (GnRH-treated or control), ovulation after $\mathrm{GnRH}$ treatment (yes or no), calving season [cool (November to May) or warm (June to September)], dairy (dairy 1 or 2), parity (primiparous or multiparous), calving-related problems (abortion, stillbirth, dystocia, twins, or retained placenta), metabolic problems (hypocalcaemia or ketosis before study enrollment), metritis (yes or no), BCS $(\leq 2.75$ or $>2.75)$, and 2-way interactions between $\mathrm{GnRH}$ treatment and the previously cited covariates. For the analysis of ovulation to GnRH-1, presence of a follicle $\geq 12 \mathrm{~mm}$ at $17 \pm$ 3 DIM and the interaction between GnRH treatment and presence of a follicle $\geq 12 \mathrm{~mm}$ at $17 \pm 3$ DIM also were included. For the analysis of ovulation to GnRH-2, presence of a follicle $\geq 12 \mathrm{~mm}$ at $20 \pm 3$ DIM and the interaction between GnRH treatment and presence of a follicle $\geq 12 \mathrm{~mm}$ at $20 \pm 3$ DIM also were included. For the analysis of overall ovulation to GnRH-1 or GnRH-2, presence of a follicle $\geq 12 \mathrm{~mm}$ at $17 \pm 3 \mathrm{DIM}$ or $20 \pm 3$ DIM and the interaction between GnRH treatment and presence of a follicle $\geq 12 \mathrm{~mm}$ at $17 \pm 3 \mathrm{DIM}$ or $20 \pm$ 3 DIM also were included. The cut-off follicle size of 12 $\mathrm{mm}$ was chosen because follicles acquire their ovulatory capacity at $12 \mathrm{~mm}$ (Sartori et al., 2001). Treatment with $\mathrm{GnRH}$ was the main effect of interest, and was forced in all models.

Hazard of ovulation up to 70 DIM and hazard to pregnancy up to 300 DIM at PD2 were analyzed by Cox's proportional hazard model using the PHREG procedure of SAS using the same explanatory variables described previously. Hazard ratio (HR) is the ratio of the hazard rates, which can be interpreted as the daily probability of a given event (ovulation or pregnancy) in each level of an explanatory variable. The variable time was the interval in days from calving to ovulation or to pregnancy. Cows that were sold or died after $28 \pm 3$ DIM or did not ovulate by 70 DIM were censored in the analysis of time to ovulation. Cows that were sold or died after $28 \pm 3$ DIM or did not conceive by 300 DIM were censored in the analysis of time to pregnancy. For the analysis of time to pregnancy, cows were considered pregnant if they were confirmed pregnant at PD2. Because of an interaction between GnRH treatment and ovulation after $\mathrm{GnRH}$ treatment in the analysis of time 
BITTAR ET AL.

Table 1. Descriptive statistics for GnRH-treated and control groups

\begin{tabular}{|c|c|c|c|c|}
\hline Variable & All cows, no. & $\mathrm{GnRH},{ }^{1}$ no. $(\%)$ & Control, ${ }^{1}$ no. $(\%)$ & $P$-value \\
\hline \multicolumn{5}{|l|}{ Location } \\
\hline Dairy 1 & 255 & $128(50.2)$ & $127(49.8)$ & 0.91 \\
\hline Dairy 2 & 225 & $112(49.8)$ & $113(50.2)$ & - \\
\hline \multicolumn{5}{|l|}{ Parity } \\
\hline Primiparous & 216 & $110(50.9)$ & $106(49.1)$ & 0.71 \\
\hline Multiparous & 264 & $130(49.2)$ & $134(50.8)$ & - \\
\hline \multicolumn{5}{|l|}{ Calving season $^{2}$} \\
\hline Warm & 321 & $161(50.1)$ & $160(49.9)$ & 0.92 \\
\hline Cool & 159 & 79 (49.7) & $80(50.3)$ & - \\
\hline \multicolumn{5}{|c|}{ Calving problems ${ }^{3}$} \\
\hline Yes & 158 & $83(52.5)$ & $75(47.5)$ & 0.43 \\
\hline No & 322 & $157(48.7)$ & $165(51.3)$ & - \\
\hline \multicolumn{5}{|c|}{ Metabolic problem ${ }^{4}$} \\
\hline Yes & 130 & $60(46.1)$ & $70(53.9)$ & 0.30 \\
\hline No & 350 & $180(51.4)$ & $170(48.6)$ & - \\
\hline \multicolumn{5}{|l|}{ Metritis $^{5}$} \\
\hline Yes & 99 & $53(53.5)$ & $46(46.5)$ & 0.43 \\
\hline No & 381 & $187(49.1)$ & $194(50.9)$ & - \\
\hline \multicolumn{5}{|l|}{$\mathrm{BCS}^{6}$} \\
\hline$\leq 2.75$ & 114 & $48(42.1)$ & $66(57.9)$ & 0.06 \\
\hline$>2.75$ & 366 & $192(52.4)$ & $174(47.6)$ & - \\
\hline \multicolumn{5}{|c|}{$\begin{array}{l}{ }^{1} \mathrm{GnRH}=\text { cows received } 100 \mu \mathrm{g} \text { of gonadorelin hydrochloride i.m. at } 17 \pm 3 \text { and } 20 \pm 3 \text { DIM }(\mathrm{n}=240) \text {; Cont } \\
=\text { cows were left untreated }(\mathrm{n}=240) .\end{array}$} \\
\hline \multicolumn{5}{|c|}{${ }^{2}$ Calving season $=$ warm (June to September) or Cool (November to May) } \\
\hline \multicolumn{5}{|c|}{${ }^{3}$ Calving problems $=$ abortion, dystocia, retained placenta, twins, or stillbirth. } \\
\hline \multicolumn{5}{|c|}{${ }^{4}$ Metabolic problems = ketosis or hypocalcemia before study enrollment. } \\
\hline \multicolumn{5}{|c|}{$\begin{array}{l}{ }^{5} \text { Metritis = fetid, reddish brownish vaginal discharge with or without fever in the first } 14 \text { DIM. } \\
{ }^{6} \mathrm{BCS}=\text { body condition score at } 17+3 \text { DIM. }\end{array}$} \\
\hline
\end{tabular}

to pregnancy; therefore, with HR not being calculated by the PHREG procedure, univariable PHREG analysis was performed to evaluate the effect of $\mathrm{GnRH}$ treatment alone, ovulation after $\mathrm{GnRH}$ treatment alone, and the interaction alone. For the interaction, a new variable containing all 4 possible combinations between $\mathrm{GnRH}$ treatment and ovulation to $\mathrm{GnRH}$ treatment was created. Kaplan-Meier plots and median days to ovulation by 70 DIM and days to pregnancy by 300 DIM were generated using MedCalc version 12.7 for Windows (MedCalc Software, Mariakerke, Belgium). Cows that had a CL at the first US were included in the Kaplan-Meier plot for time to pregnancy by 300 DIM according to incidence of ovulation after $\mathrm{GnRH}$ treatment to serve as a reference. Statistical significance was considered when $P \leq 0.05$.

\section{RESULTS}

\section{Descriptive Statistics}

Descriptive statistics are shown in Table 1. None of the variables was significantly different between GnRHtreated and control cows.

\section{Ovulation}

Ovulatory responses are presented in Table 2. An interaction $(P=0.03)$ was detected between $\mathrm{GnRH}$ treatment and presence of a follicle $\geq 12 \mathrm{~mm}$ at $17 \pm 3$ DIM on ovulation to GnRH-1. Cows that had a follicle $\geq 12 \mathrm{~mm}$ at $17 \pm 3 \mathrm{DIM}$ and received $\mathrm{GnRH}$ had greater ovulation to GnRH-1 than control cows. In contrast, no difference in ovulation incidences was detected between GnRH-treated and control cows that did not have a follicle $\geq 12 \mathrm{~mm}$ at $17 \pm 3$ DIM. Ovulation to GnRH-1 was also affected by parity, BCS at $17 \pm 3$ DIM, and prevalence of metabolic problems before study enrollment. Multiparous cows, cows with BCS $>2.75$, and cows without metabolic problems had a greater ovulatory response to GnRH-1 than primiparous cows, cows with $\mathrm{BCS} \leq 2.75$, and cows with metabolic problems, respectively. An interaction $(P=0.009)$ was detected between GnRH treatment and parity on ovulation to GnRH-2. Nonetheless, GnRH treatment increased ovulation to GnRH-2 in both primiparous and multiparous, although the increase was greater in primiparous cows. Ovulation to GnRH-2 also was affected by presence of a follicle $\geq 12 \mathrm{~mm}$ at $20 \pm 3 \mathrm{DIM}$ and by calving season. Cows that did not have a follicle $\geq 12 \mathrm{~mm}$ at $20 \pm 3$ DIM and cows that calved in the warm season had greater ovulation to GnRH-2 than cows that had a follicle $\geq 12 \mathrm{~mm}$ at $20 \pm 3 \mathrm{DIM}$ and cows that calved in the cool season, respectively. An interaction $(P=0.02)$ was detected between GnRH treatment and presence of a follicle $\geq 12 \mathrm{~mm}$ at $17 \pm 3$ DIM or $20 \pm 3$ DIM on 
overall ovulation to GnRH-1 or GnRH-2. Cows that had a follicle $\geq 12 \mathrm{~mm}$ at $17 \pm 3 \mathrm{DIM}$ or $20 \pm 3 \mathrm{DIM}$ and received $\mathrm{GnRH}$ had greater overall ovulation to GnRH-1 or GnRH-2 than control cows. In contrast, no difference in ovulation risk was observed between GnRH-treated and control cows that did not have a follicle $\geq 12 \mathrm{~mm}$ at $17 \pm 3$ DIM or $20 \pm 3$ DIM. Overall ovulation to GnRH-1 or GnRH-2 was also affected by calving season. Cows that calved in the warm season had greater ovulation to GnRH-1 or GnRH-2 than cows that calved in the cool season.

Kaplan-Meier survival curve for time to ovulation is shown in Figure 2. Median days to ovulation through 70 DIM was decreased $(P=0.003)$ by $8 \mathrm{~d}$ for GnRHtreated cows compared with control cows (24 vs. $32 \mathrm{~d}$ ).

\section{Uterine Health Outcomes}

Uterine health outcomes are presented in Table 3. Early postpartum administration of $\mathrm{GnRH}$ did not affect the prevalence of clinical endometritis or cyto- logical endometritis. Prevalence of clinical endometritis was increased in cows that had calving problems and metritis compared with cows that did not have these conditions. Cows that had metritis also had increased prevalence of cytological endometritis.

\section{Reproductive Outcomes}

Pregnancy per AI and pregnancy loss data are presented in Table 4. Pregnancy per AI at PD1 and PD2 was similar for GnRH-treated and control cows. Cows that ovulated by $24 \pm 3$ DIM had greater PAI at PD1. As a reference, GnRH treated cows that did and did not ovulate by $24 \pm 3$ DIM had PAI of 40.9 and $25 \%$ at PD1 and PAI of 37.7 and $25 \%$ at PD2, respectively. Control cows that did and did not ovulate by $24 \pm 3$ DIM had PAI of 40.7 vs. $36.8 \%$ at PD1 and 30.1 and $32.8 \%$ at PD2, respectively. Although the difference in PAI between cows that did or did not ovulate after GnRH treatment was considerably greater for GnRHtreated cows than for control cows, no interaction was

Table 2. Final multivariable logistic regression models for the effect of GnRH administration at $17 \pm 3$ and $20 \pm 3$ DIM on ovulatory response

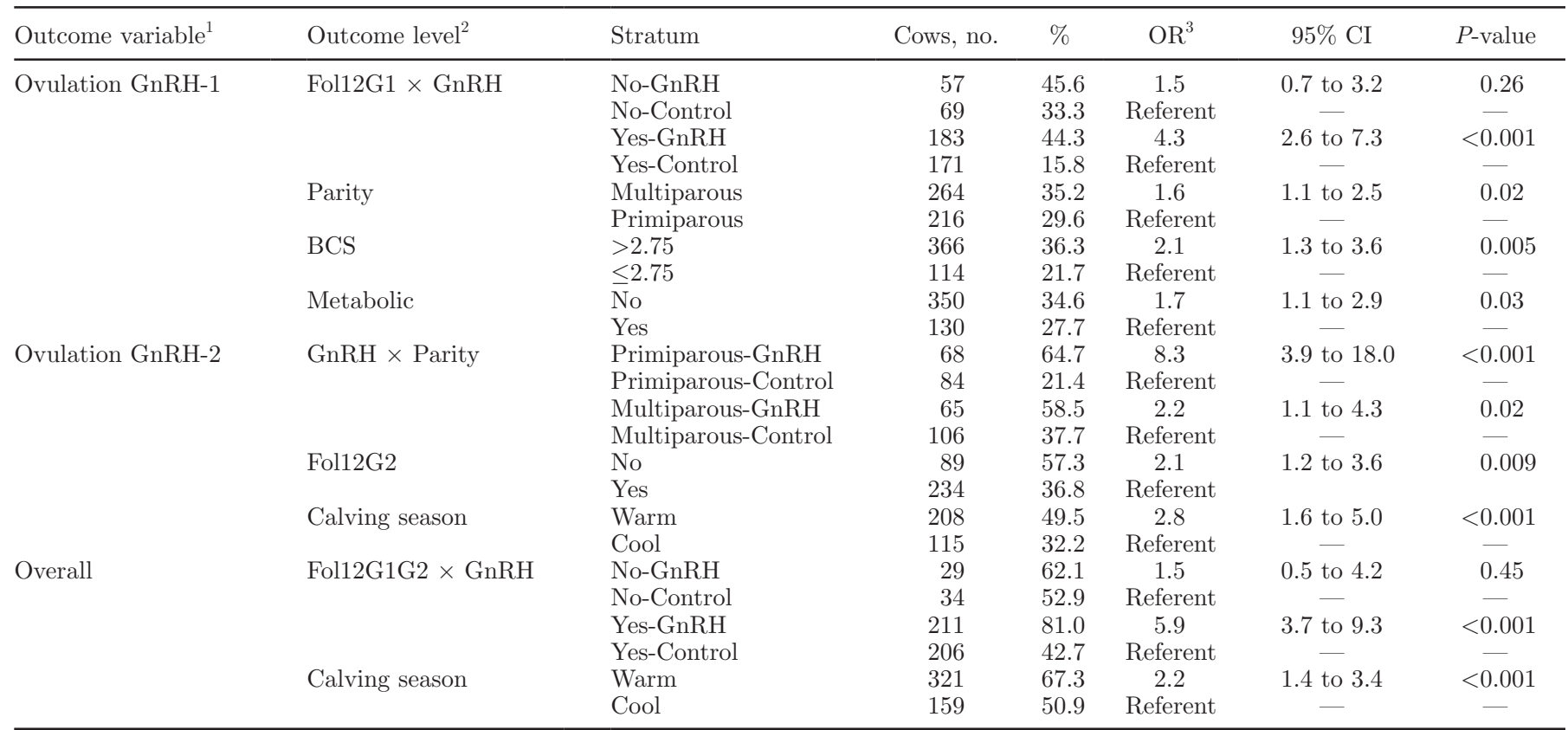

${ }^{1} \mathrm{GnRH}=$ cows received $100 \mu \mathrm{g}$ of gonadorelin hydrochloride i.m. at $17 \pm 3$ (GnRH-1) and $20 \pm 3$ DIM (GnRH-2); Control: cows were left untreated. Ovulation to GnRH-1 was determined by appearance of a corpus luteum (CL) at the subsequent ultrasonography at $20 \pm 3$ DIM or the disappearance of a follicle $\geq 12 \mathrm{~mm}$ present in the ultrasound at $17 \pm 3$ DIM and the appearance of a CL at $24 \pm 3$ DIM. After excluding cows that had already ovulated to GnRH-1 $(\mathrm{n}=157)$, ovulation to GnRH-2 was determined by the appearance of a CL at $24 \pm 3$ DIM or by the disappearance of a follicle $\geq 12 \mathrm{~mm}$ present in the ultrasound at $20 \pm 3 \mathrm{DIM}$ and the appearance of a CL in the ultrasound at $28 \pm 3 \mathrm{DIM}$. Therefore, overall ovulation to GnRH-1 or GnRH-2 was considered in cows that had ovulated by $24 \pm 3$ DIM and had a CL formed by $28 \pm 3$ DIM.

${ }^{2}$ Fol12G1 $\times \mathrm{GnRH}=$ interaction between presence of a follicle $\geq 12 \mathrm{~mm}$ at GnRH-1 (yes or no) and GnRH treatment; Fol12G2 $=$ presence of a follicle $\geq 12 \mathrm{~mm}$ at GnRH-2; Fol12G1G2 $\times \mathrm{GnRH}=$ interaction between presence of a follicle $\geq 12 \mathrm{~mm}$ at $\mathrm{GnRH}-1$ or GnRH-2 and GnRH treatment; BCS = body condition score at $17 \pm 3$ DIM; Metabolic = metabolic problems (ketosis or hypocalcemia before study enrollment); Calving season $=$ warm (June to September) or cool (November to May).

${ }^{3} \mathrm{OR}=$ odds ratio. 
Table 3. Final multivariable logistic regression models for the effect of GnRH administration at $17 \pm 3$ and $20 \pm 3$ DIM on prevalence of clinical $^{1}$ and cytological endometritis ${ }^{2}$ in dairy cows

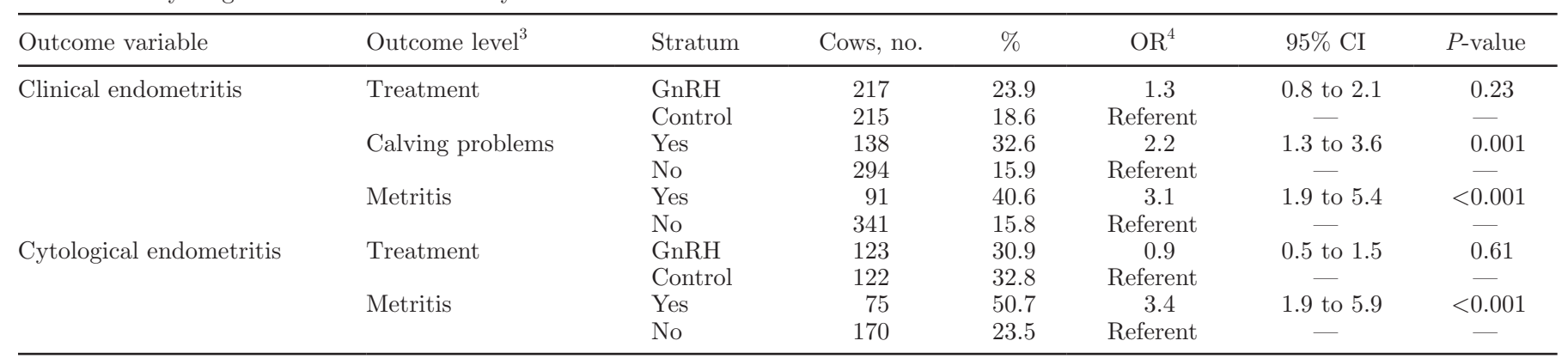

${ }^{1}$ Clinical endometritis characterized by mucopurulent or purulent discharge at 35 DIM.

${ }^{2}$ Cytological endometritis characterized by presence of $\geq 10 \%$ neutrophils in the uterine cytology at 35 DIM. Cytological endometritis was only evaluated in dairy 1.

${ }^{3}$ Treatment $=$ cows received $100 \mu \mathrm{g}$ of gonadorelin hydrochloride i.m. at $17 \pm 3$ and $20 \pm 3$ DIM $(\mathrm{GnRH})$ or cows were left untreated (Control); Calving problems $=$ abortion, dystocia, retained placenta, twins, or stillbirth; Metritis $=$ fetid, reddish brownish vaginal discharge with or without fever in the first 14 DIM.

${ }^{4} \mathrm{OR}=$ odds ratio.

noted between GnRH treatment and ovulation after GnRH treatment at PD1 $(P=0.12)$ or PD2 $(P=0.08)$. As a reference, cows that had a CL at the first US (unenrolled cows) had 41.1\% (58/141) PAI at PD1 and $38.3 \%$ (54/141) PAI at PD2. Cows with BCS $>2.75$ at study enrollment and cows in dairy 1 had greater PAI at PD1 and PD2 (Table 4).

Pregnancy loss from PD1 to PD2 was greater for control cows compared with GnRH-treated cows. Pregnancy loss was also greater for cows that had ovulated

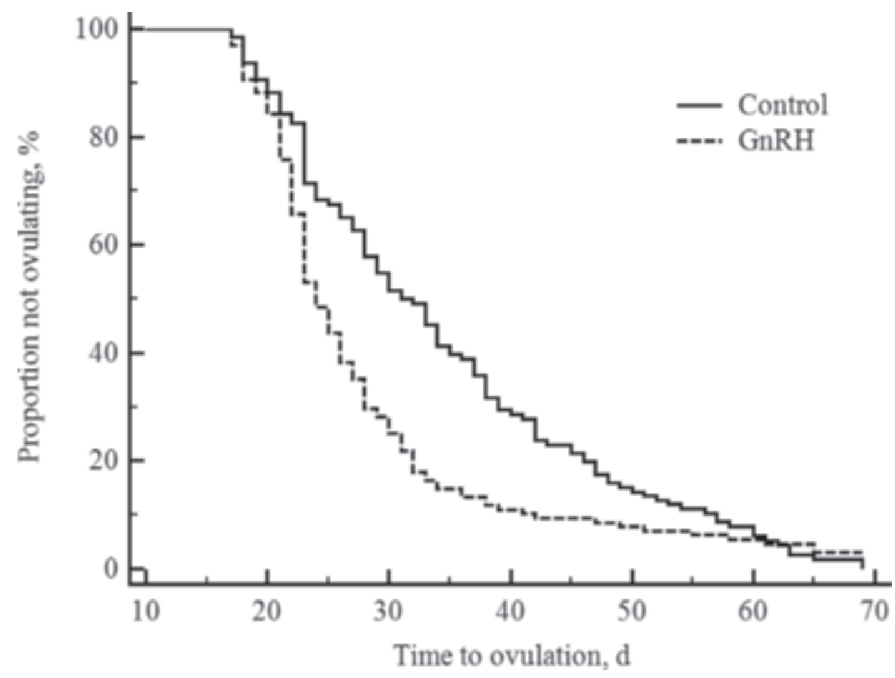

Figure 2. Kaplan-Meier survival curves for time to first postpartum ovulation up to $70 \mathrm{DIM}$ for the $\mathrm{GnRH}$-treated group (dashed line; $\mathrm{n}=128$ ) and control group (solid line; $\mathrm{n}=127$ ) in dairy 1 . The GnRH-treated cows received a 100- $\mu \mathrm{g}$ injection of gonadorelin hydrochloride i.m. at $17 \pm 3$ and $20 \pm 3$ DIM, and the control group remained untreated. Median days to ovulation and proportion of cows that ovulated by 70 DIM were $24 \mathrm{~d}, 96.8 \%$ and $32 \mathrm{~d}, 97.6 \%$ for $\mathrm{GnRH}-$ treated and control cows, respectively $(P=0.003)$. by $24 \pm 3$ DIM and cows that had metritis. As a reference, GnRH-treated cows that did and did not ovulate after GnRH treatment had pregnancy loss of 8 and $0 \%$, respectively, and control cows that did and did not ovulate had pregnancy losses of 26.1 and $10.8 \%$, respectively. Unenrolled cows that had a CL at the first US had $6.9 \%$ pregnancy loss.

Hazard of pregnancy is presented in Table 5. An interaction was observed between GnRH treatment and ovulation after GnRH treatment on the hazard of pregnancy up to $300 \mathrm{DIM}(P=0.05)$. The univariable PHREG models showed that hazard of pregnancy up to 300 DIM was not affected by GnRH treatment but was affected by ovulation by $24 \pm 3$ DIM with cows that ovulated having greater hazard of pregnancy than for cows that did not ovulate (Table 5). The interaction showed that GnRH-treated cows that ovulated by 24 \pm 3 DIM had increased hazard of pregnancy compared with GnRH-treated cows that failed to ovulate, but no difference in the hazard of pregnancy was seen between control cows that ovulated and control cows that did not ovulate.

Kaplan-Meier survival curves for time to pregnancy are shown in Figures 3, 4 and 5. Median days to pregnancy and proportion of cows pregnant (in parenthesis) by 300 DIM for GnRH-treated cows and control cows were $122(78.8 \%)$ and $136(76.3 \%)$, respectively (Figure 3 ). Median days to pregnancy and proportion of cows pregnant (in parenthesis) by 300 DIM for unenrolled cows that had a CL at the first US, cows that ovulated by $24 \pm 3$ DIM, and cows that did not ovulate by 24 \pm 3 DIM were 120 (78.3\%), $121(81.9 \%)$, and $155 \mathrm{~d}$ (70.5\%; Figure 4$)$. Cows that ovulated by $24 \pm 3$ DIM had similar $(P=0.9)$ time to pregnancy compared with unenrolled cows that had a CL at the first US, and 
Table 4. Final multivariable logistic regression models for the effects of GnRH administration at $17 \pm 3$ and $20 \pm 3$ DIM in dairy cows without a corpus luteum (CL) at study enrolment on pregnancy per AI diagnosed in dairy 1 at $32 \mathrm{~d}$ after AI and in dairy 2 at $39 \pm 3 \mathrm{~d}$ after AI defined as pregnancy diagnosis 1 (PD1), and reconfirmed in dairy 1 at $74 \mathrm{~d}$ after AI and in dairy 2 at $84 \pm 3 \mathrm{~d}$ after AI defined as pregnancy diagnosis 2 (PD2), and pregnancy loss (PL) from PD1 to PD2

\begin{tabular}{|c|c|c|c|c|c|c|c|}
\hline Outcome variable & Outcome level ${ }^{1}$ & Stratum & Cows, no. & $\%$ & $\mathrm{OR}^{2}$ & $95 \% \mathrm{CI}$ & $P$-value \\
\hline \multirow{4}{*}{ PD1 } & Treatment & Control & 228 & 38.6 & Referent & - & - \\
\hline & \multirow[t]{2}{*}{ BCS } & $>2.75$ & 355 & 41.4 & 1.8 & 1.1 to 3.1 & 0.01 \\
\hline & & $\leq 2.75$ & 104 & 26.9 & Referent & - & - \\
\hline & Dairy & 1 & 240 & 45.4 & 2.0 & 1.4 to 2.9 & $<0.001$ \\
\hline & Treatment & Control & 228 & 31.5 & Referent & - & - \\
\hline & \multirow[t]{2}{*}{$\mathrm{BCS}$} & $>2.75$ & 355 & 36.3 & 1.8 & 1.1 to 3.1 & 0.02 \\
\hline & & $\leq 2.75$ & 104 & 23.1 & Referent & - & - \\
\hline & \multirow[t]{2}{*}{ Dairy } & 1 & 240 & 39.6 & 1.8 & 1.2 to 2.7 & 0.004 \\
\hline & & 2 & 219 & 26.5 & Referent & - & - \\
\hline \multirow{2}{*}{$\mathrm{PL}$} & \multirow[t]{2}{*}{ Treatment } & GnRH & 87 & 6.8 & 0.16 & 0.05 to 0.5 & $<0.01$ \\
\hline & & Control & 88 & 18.1 & Referent & - & - \\
\hline
\end{tabular}

${ }^{1}$ Treatment $=$ cows received $100 \mu \mathrm{g}$ of gonadorelin hydrochloride i.m. at $17 \pm 3$ and $20 \pm 3$ DIM $(\mathrm{GnRH})$ or cows were left untreated $(\mathrm{Control})$; Ovulation $=$ ovulated by $24 \pm 3$ DIM and had a CL formed by $28 \pm 3$ DIM; BCS = body condition score at $17 \pm 3$ DIM. Calving problems $=$ abortion, dystocia, retained placenta, twins, or stillbirth; Metritis = fetid, reddish brownish vaginal discharge with or without fever in the first 14 DIM.

${ }^{2} \mathrm{OR}=$ odds ratio.

both had shorter $(P<0.05)$ time to pregnancy compared with cows that did not ovulate by $24 \pm 3$ DIM. Median days to pregnancy and proportion of cows pregnant (in parenthesis) by 300 DIM for GnRH-treated cows that ovulated, GnRH-treated cows that did not ovulate, control cows that ovulated, and control cows that did not ovulate by 24 DIM were 119 (80.9\%), 168 (58.9\%), $133(83.4 \%)$, and $140 \mathrm{~d}(74.9 \%)$, respectively (Figure 5).

\section{DISCUSSION}

The randomized clinical trial reported herein was designed to evaluate the effect of $\mathrm{GnRH}$ administration at $17 \pm 3$ and $20 \pm 3$ DIM on ovulation responses, prevalence of clinical endometritis and cytological endometritis, and reproductive outcomes. Our observation of increased ovulation risk after GnRH-1 and GnRH-2 and overall ovulation risk corroborate with previous research reporting that exogenous GnRH can induce ovulation from 10 to 30 DIM (Britt et al., 1974). As expected, GnRH was most effective in cows that were expected to have a follicle that had achieved ovulatory capacity. Although others have shown ovulation risk similar to the ones observed herein using only 1 dose of GnRH (Benmrad and Stevenson, 1986), if only 1 injection was administered, only $44.6 \%$ of the cows would

Table 5. Univariable Cox PH models for the effects of GnRH administration at $17 \pm 3$ and $20 \pm 3$ DIM on time to pregnancy up to 300 DIM

\begin{tabular}{llcccc}
\hline Outcome variable $^{1}$ & Stratum & Cows, no. & HR $^{2}$ & 95\% CI & $P$-value \\
\hline Treatment $^{3}$ & GnRH & 240 & 1.0 & 0.8 to 1.2 & 0.91 \\
Ovulation & Control & 240 & Referent & - & - \\
& Yes & 297 & 1.4 & 1.1 to 1.8 & $<0.01$ \\
Treatment & No ovulation & 183 & Referent & - & - \\
& GnRH-Ov & 189 & 2.0 & 1.4 to 2.9 & $<0.001$ \\
& GnRH-NoOv & 51 & Referent & - & - \\
& Control-Ov & 132 & Coferent & - & - \\
\hline
\end{tabular}

${ }^{1}$ Treatment $=$ cows received $100 \mu \mathrm{g}$ of gonadorelin hydrochloride i.m. at $17 \pm 3$ and $20 \pm 3$ DIM $(\mathrm{GnRH})$ or cows were left untreated (Control); Ovulation = ovulated by $24 \pm 3$ DIM and had a CL formed by $28 \pm 3$ DIM; Treatment $\times$ ovulation $=$ interaction between $\mathrm{GnRH}$ treatment $(\mathrm{GnRH}$ or Control) and ovulation after GnRH treatment $(\mathrm{Yes}=\mathrm{Ov}$ and $\mathrm{No}=\mathrm{NoOv})$.

${ }^{2} \mathrm{HR}=$ hazard ratio. 


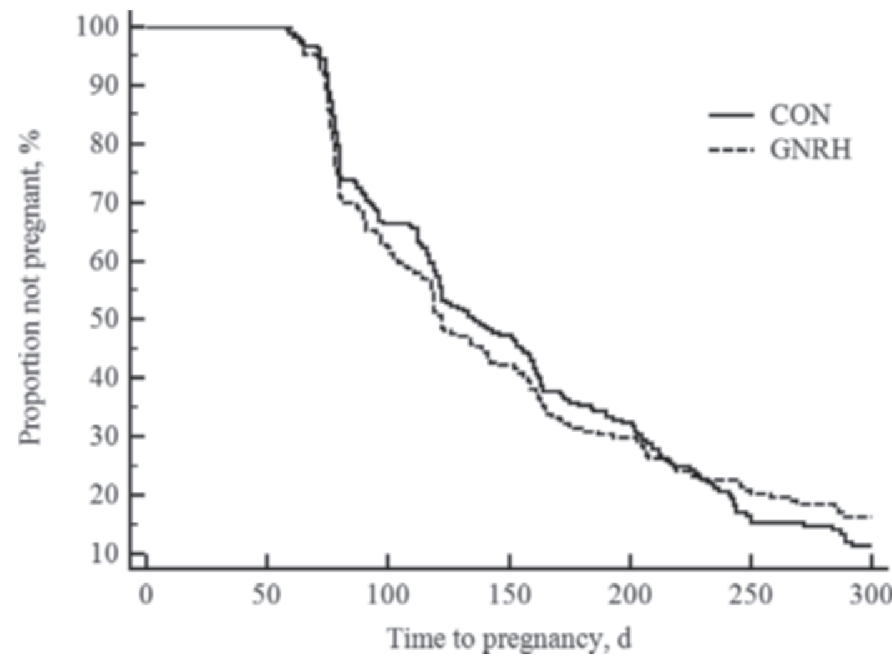

Figure 3. Kaplan-Meier survival curves for time to pregnancy at pregnancy diagnosis 2 up to 300 DIM for the GnRH-treated group (GNRH; dashed line; $\mathrm{n}=240$ ) and control group (CON; solid line; $\mathrm{n}$ $=240$ ). The GnRH-treated group (cows received a 100- $\mu \mathrm{g}$ injection of gonadorelin hydrochloride i.m. at $17 \pm 3$ and $20 \pm 3$ DIM) and control group (no hormonal injection) had median days to pregnancy and proportion of cows pregnant by 300 DIM of $122 \mathrm{~d}, 78.8 \%$ and $136 \mathrm{~d}$, $76.3 \%$, respectively (univariable survival analysis; $P=0.93$ ).

have responded. This ovulatory response would have been more than twice the ovulation risk than in the control group (20.9\%), or a 23.7 percentage point in-

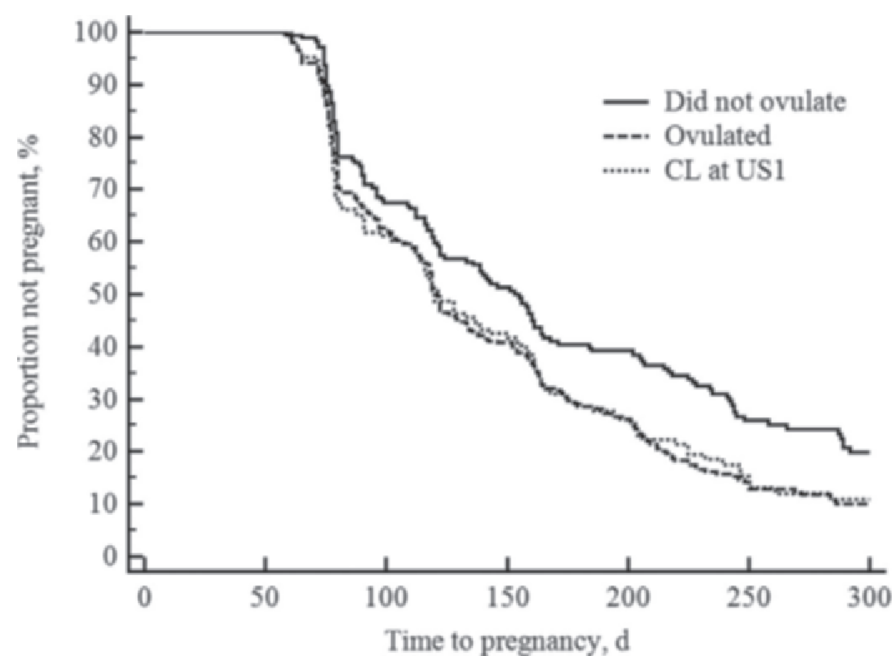

Figure 4. Kaplan-Meier survival curves for time to pregnancy at pregnancy diagnosis up to 300 DIM according to ovulation status for cows that entered the study without a corpus luteum (CL) and did not ovulate (solid line; $\mathrm{n}=183$ ), for cows that entered the study without CL and ovulated by $24 \pm 3$ DIM (dashed line; $\mathrm{n}=297$ ), and for cows with a CL in the beginning of the study [CL at first ultrasound (US1); dotted line; $\mathrm{n}=147]$. Median days to pregnancy and proportion of cows pregnant by 300 DIM of $155 \mathrm{~d}, 70.5 \%$; $121 \mathrm{~d}, 81.9 \%$; and $120 \mathrm{~d}, 78.3 \%$ for cows that did not ovulate by $24 \pm 3$ DIM, cows that ovulated by $24 \pm 3$ DIM, and cows with CL at study enrollment, respectively (univariable survival analysis; $P=0.003$ ).

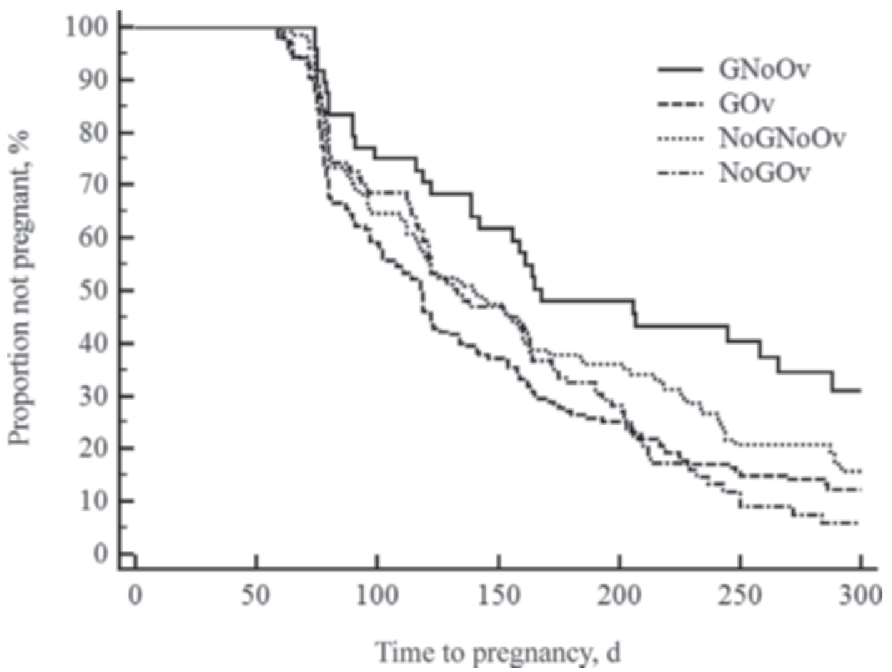

Figure 5. Kaplan-Meier survival curves for time to pregnancy at pregnancy diagnosis 2 up to 300 DIM according to treatment and ovulation status for GnRH-treated cows that ovulated (GOv; dashed line; $\mathrm{n}=189$ ) or did not ovulate by $24 \pm 3$ DIM (GNoOv; solid line; $\mathrm{n}=51$ ) and control cows that ovulated (NoGOv; dash-dotted line; $\mathrm{n}$ $=108$ ) or did not ovulate by $24 \pm 3$ DIM (NoGNoOv; dotted line; $\mathrm{n}$ $=132$; interaction between treatment and ovulation, $P=0.05)$. The GOv cows had increased hazard of pregnancy (HR) compared with GNoOv $(\mathrm{HR}=2.0 ; 95 \% \mathrm{CI}=1.4-2.9 ; P<0.001)$, or NoGNoOv $(\mathrm{HR}=1.3 ; P=0.05)$, and similar to NoGOv $(\mathrm{HR}=1.1 ; P=0.70)$. Control cows that did or that did not ovulate had similar hazard of pregnancy among themselves $(\mathrm{HR}=1.2 ; P=0.17)$ and greater hazard of pregnancy than GnRH-treated cows that did not ovulate $(P=0.002$ and 0.033 , respectively). Median days to pregnancy and proportion of cows pregnant by 300 DIM were $119 \mathrm{~d}, 80.9 \% ; 168 \mathrm{~d}, 58.9 \%$; $133 \mathrm{~d}$, $83.4 \%$; and $140 \mathrm{~d}, 74.9 \%$ for GOv, GNoOv, NoGOv, and NoGNoOv cows, respectively.

crease. This improvement is in agreement with a recent report where only 1 injection of $100 \mu \mathrm{g}$ of $\mathrm{GnRH}$ was given at $29.2 \pm 5.2 \mathrm{DIM}$ and ovulation was improved by 17.9 percentage units ( 70.9 vs. $53.0 \%$; Jeong et al., 2013). Therefore, it seems plausible that 2 injections of $\mathrm{GnRH}$ are needed to optimize ovulation risk. The interval of $3.5 \mathrm{~d}$ would allow follicles that did not respond to the first GnRH to grow another 5 to $9 \mathrm{~mm}$ (growth of 1.5 to $2.6 \mathrm{~mm} / \mathrm{d}$; Ginther et al., 1997), which would allow them to gain ovulatory capacity if they were at least $6 \mathrm{~mm}$ at GnRH-1 (Sartori et al., 2001). It is possible that waiting another 1 or $2 \mathrm{~d}$ would have increased ovulatory response even further, but this needs to be investigated.

Pregnancy to the first service and time to pregnancy were not different for GnRH-treated and control cows, corroborating previous reports (Cavestany and Foote, 1985; Foote and Riek, 1999). Nonetheless, in contrast to previous findings, no negative (Etherington et al., 1984; Stevenson and Call, 1988; Padula and Macmillan, 2002) or positive (Nash et al., 1980; Benmrad and Stevenson, 1986; Jeong et al., 2013) effect of early postpartum $\mathrm{GnRH}$ administration was observed. In the most recent 
study (Jeong et al., 2013), GnRH administration in healthy cows (cows without dystocia, retained placenta, metritis, clinical endometritis, or metabolic diseases) without a CL at $29 \pm 5$ DIM increased ovulation risk by 18 percentage points ( 71 vs. $53 \%$ ), increased PAI to the first AI by 10 percentage points (39 vs. 29\%), and decreased time to pregnancy up to 210 DIM by $16 \mathrm{~d}$ (117 vs. 133 d). In our study, cows that were induced to ovulate after GnRH treatment had increased fertility compared with controls; however, cows that did not respond to GnRH treatment had decreased fertility compared with controls (interaction between $\mathrm{GnRH}$ treatment and ovulation after GnRH treatment; Figure 5). Therefore, the overall effect of GnRH treatment was nil. Our interpretation is that GnRH served as a marker to separate cows that were doing reasonably well with regard to uterine health and metabolic status, but had delayed ovulation, from cows that were in poorer health and metabolic status, and probably in deeper anestrus (no follicle development beyond $9 \mathrm{~mm}$ ); hence, not responding to 2 injections of GnRH 3.5 d apart. Because Jeong et al. (2013) only administered GnRH once and only used healthy cows, it is possible that cows that did not respond to GnRH were in a better health and metabolic status; therefore, those cows had similar fertility compared with the control cows that did not ovulate, which in turn would result in an overall increase in fertility for the GnRH-treated cows.

Pregnancy loss is an important component of herd reproductive performance. In the present study, GnRHtreated cows had lesser pregnancy loss compared with control cows. To our knowledge, this is the first time that early postpartum GnRH treatment is associated with a reduction in pregnancy loss. Because cows that remain anovulatory by the end of the voluntary waiting have been shown to have increased pregnancy loss (Santos et al., 2004), a potential explanation for decreased pregnancy loss in the GnRH treatment would be the increased ovulation risk by $24 \pm 3$ DIM. In contrast, pregnancy loss was actually greater in cows that ovulated between $17 \pm 3$ and $24 \pm 3$ DIM. In fact, all the pregnancy losses in the GnRH-treated group and most of the losses in the control group came from the cows that ovulated after $\mathrm{GnRH}$ treatment or that ovulated spontaneously by 24 DIM. Interestingly, pregnancy loss in unenrolled cows that had a CL at $17 \pm 3$ DIM was the lowest, therefore indicating that spontaneous early ovulation had no negative effect on pregnancy loss. Hence, at this point it is not clear why $\mathrm{GnRH}$ administration resulted in decreased pregnancy loss and ovulation between $17 \pm 3$ and $24 \pm 3$ DIM resulted in increased pregnancy loss. A type 1 error is possible; therefore, further research is needed to confirm the beneficial effect of $\mathrm{GnRH}$ administration on pregnancy loss and the negative effect of ovulation between $17 \pm$ 3 and $24 \pm 3$ DIM on pregnancy loss.

It has been observed that $\mathrm{GnRH}$ administration early postpartum increased frequency of pyometra (Etherington et al., 1984). Herein we thoroughly evaluated uterine health by diagnosing clinical endometritis and cytological endometritis, and found no negative effect on the prevalence of either disease. Our results agree with Stevenson and Call (1988), where no evidence of negative effects of $\mathrm{GnRH}$ administration early postpartum on uterine health was observed. Calving-related problems significantly increased the odds of having clinical endometritis, and metritis increased the odds of having both clinical endometritis and cytological endometritis, which agrees with previous reports (Benzaquen et al., 2007; Rutigliano et al., 2008).

Body condition score $>2.75$ at $17 \pm 3$ DIM had a positive effect on ovulation after GnRH-1 and on PAI at PD1 and PD2. Greater BCS loss is associated with a more pronounced state of negative energy balance, which has been shown to delay resumption of postpartum ovarian cyclicity and ovulation (Beam and Butler, 1999; Santos et al., 2009); therefore, it is expected that cows that lost less BCS would have greater BCS at $17 \pm 3$ DIM. In addition, several studies have shown improved cyclicity and fertility for cows with greater BCS (López-Gatius et al., 2003; Santos et al., 2009).

The observation of greater ovulation risk in the warm season agrees with previous reports where ovulation was increased in the warm season (Hansen and Hauser, 1983; Walsh et al., 2007). Photoperiod may affect follicle development because melatonin is decreased with increased day length, and melatonin has been shown to decrease LH concentrations in ovariectomized cows (Rhodes et al., 1979). An interaction was detected between GnRH treatment and parity on ovulation to GnRH-2. This interaction was mainly because of a lower spontaneous ovulation in primiparous control cows compared with multiparous control cows. Previous studies have shown a decrease in resumption of ovulation for primiparous compared with multiparous cows (Santos et al., 2009), which may be related to greater incidence of metritis (Goshen and Shpigel, 2006) and greater degree of negative energy balance (Wathes et al., 2007), which are known to affect resumption of ovulation postpartum (Beam and Butler, 1999).

Dairy had an effect on PAI at first service, in which dairy 1 had greater PAI than dairy 2. Differences in PAI between dairies may arise from a multitude of cowlevel and herd-level factors that go beyond the scope of the current study. Our main goal in including dairy as a fixed effect was to be able to test for interactions between GnRH-treatment and dairy on response to GnRH treatment; however, one was not observed, in- 
dicating that $\mathrm{GnRH}$ treatment was equally effective in inducing ovulation in both dairies. Therefore, it is safe to assume that a similar response to $\mathrm{GnRH}$ treatment may be expected in dairies with similar characteristics to the ones used herein.

Metritis in our study was associated with increased incidence of pregnancy loss, and, interestingly, not many studies have presented similar findings. A recent study observed that metritis increased the odds of pregnancy loss by 4 times compared with cows without metritis (Ribeiro et al., 2013). As observed herein, cows with metritis had greater incidence of clinical endometritis and cytological endometritis, which are diseases known to affect pregnancy loss (Galvão et al., 2009, Lima et al., 2013). The inflammatory process associated with uterine diseases led to occlusion of the endometrial glands, dilation of underlying glands with a deposit of connective tissue, and formation of scar tissue in the uterus, which may affect placentation and maintenance of pregnancy. Furthermore, activation of the inflammatory cascade stimulates the release of $\mathrm{PGF}_{2 \alpha}$ from the endometrium and luteal cells, hence inducing luteolysis (Skarzynski et al., 2005).

\section{CONCLUSIONS}

Administration of 2 doses of $\mathrm{GnRH}$ analog, at 17 and at $20 \pm 3$ DIM in lactating Holstein cows, successfully induced ovulation by $24 \pm 3$ DIM. Treatment with GnRH did not affect uterine health or PAI to the first service, although it did decrease pregnancy loss. Time to pregnancy was not affected by GnRH treatment because, although the hazard of pregnancy was increased in cows that responded to GnRH treatment, the hazard of pregnancy was decreased in cows that did not respond to $\mathrm{GnRH}$ treatment. In summary, early postpartum administration of $\mathrm{GnRH}$ induced ovulation without affecting uterine health, but failed to improve PAI or time to pregnancy, although it reduced pregnancy loss.

\section{ACKNOWLEDGMENTS}

The authors thank the management team, Eric Diepersloot and Jay Lemmermen and staff from the University of Florida Institute of Food and Agricultural Sciences Dairy Unit, and the owner, Don Bennink, and staff of North Florida Holsteins Dairy (Bell, FL) for allowing the use of their cows for this experiment. Our thanks extend to undergraduate and graduate students of University of Florida for the essential help in part of the data collection. We thank Zoetis Inc. (Florham Park, NJ) for donation of Factrel, and, finally, Southeast Milk Inc. (Belleview, FL). Milk Check-Off program and the College of Veterinary Medicine at University of Florida for the financial support to conduct the experiment.

\section{REFERENCES}

Beam, S. W., and W. R. Butler. 1999. Effects of energy balance on follicular development and first ovulation in postpartum dairy cows. J. Reprod. Fertil. Suppl. 54:411-424.

Benmrad, M., and J. S. Stevenson. 1986. Gonadotropin-releasing hormone and prostaglandin $\mathrm{F}_{2 \alpha}$ for postpartum dairy cows: Estrous, ovulation, and fertility traits. J. Dairy Sci. 69:800-811.

Benzaquen, M. E., C. A. Risco, L. F. Archbald, P. Melendez, M. J. Thatcher, and W. W. Thatcher. 2007. Rectal temperature, calving-related factors, and the incidence of puerperal metritis in postpartum dairy cows. J. Dairy Sci. 90:2804-2814.

Britt, J. H., D. S. Harrison, and D. A. Morrow. 1977. Frequency of ovarian follicular cysts, reasons for culling, and fertility in Holstein-Friesian cows given gonadotropin-releasing hormone at two weeks after parturition. Am. J. Vet. Res. 38:749-751.

Britt, J. H., R. J. Kittok, and D. S. Harrison. 1974. Ovulation, estrus and endocrine response after $\mathrm{GnRH}$ in early postpartum cows. J. Anim. Sci. 39:915-919.

Caraviello, D. Z., K. A. Weigel, P. M. Fricke, M. C. Wiltbank, M. J. Florent, N. B. Cook, K. V. Nordlund, N. R. Zwald, and C. L. Rawson. 2006. Survey of management practices on reproductive performance of dairy cattle on large US commercial farms. J. Dairy Sci. 89:4723-4735.

Cavestany, D., and R. H. Foote. 1985. Reproductive performance of Holstein cows administered GnRH analog HOE 766 (Buserelin) 26 to 34 d postpartum. J. Anim. Sci. 61:224-233.

Darwash, A. O., G. E. Lamming, and J. A. Wooliams. 1997. The phenotypic association between the interval to postpartum ovulation and traditional measures of fertility in dairy cattle. J. Anim. Sci. 65:9-16.

De Vries, A. 2006. Economic value of pregnancy in dairy cattle. J. Dairy Sci. 89:3876-3885.

Dubuc, J., T. F. Duffield, K. E. Leslie, J. S. Walton, and S. J. LeBlanc. 2010. Definitions and diagnosis of postpartum endometritis in dairy cows. J. Dairy Sci. 93:5225-5233.

Etherington, W. G., W. T. K. Bosu, S. W. Martin, J. F. Cote, P. A. Doig, and K. E. Leslie. 1984. Reproductive performance in dairy cows following postpartum treatment with gonadotrophin-releasing hormone and/or prostaglandin: A field trial. Can. J. Comp. Med. 48:245-250.

Ferguson, J. D., D. T. Galligan, and N. Thomsen. 1994. Principal descriptors of body condition score in Holstein cows. J. Dairy Sci. $77: 2695-2703$

Foote, R. H., and P. M. Riek. 1999. Gonadotropin-releasing hormone improves reproductive performance of dairy cows with slow involution of the reproductive tract. J. Anim. Sci. 77:12-16.

Galvão, K. N., M. Frajblat, W. R. Butler, S. B. Brittin, C. L. Guard, and R. O. Gilbert. 2010. Effect of early postpartum ovulation on fertility in dairy cows. Reprod. Domest. Anim. 45:e207-e211.

Galvão, K. N., L. F. Greco, J. M. Vilela, M. F. Sá Filho, and J. E. P. Santos. 2009. Effect of intrauterine infusion of ceftiofur on uterine health and fertility in dairy cows. J. Dairy Sci. 92:1532-1542.

Ginther, O. J., K. Kot, L. J. Kulick, and M. C. Wiltbank. 1997. Emergence and deviation of follicles during the development of follicular waves in cattle. Theriogenology 48:75-87.

Goshen, T., and N. Y. Shpigel. 2006. Evaluation of intrauterine antibiotic treatment of clinical metritis and retained fetal membranes in dairy cows. Theriogenology 66:2210-2218.

Hansen, P. J., and E. R. Hauser. 1983. Genotype $\times$ environmental interactions on reproductive tracts of bovine females. III. Seasonal variation in postpartum reproductive traits as influenced by genotype, suckling and dietary regimen. J. Anim. Sci. 56:1362-1369.

Jeong, J. K., H. G. Kang, T. Y. Hur, and I. H. Kim. 2013. Gonadotropin-releasing hormone administration to dairy cows without a corpus luteum 4 weeks after calving increases reproductive 
performance. Reprod. Dom. Anim. 48:931-935. http://dx.doi. org $/ 10.1111 /$ rda. 12188

Lima, F. S., R. S. Bisinotto, E. S. Ribeiro, L. F. Greco, H. Ayres, M. G. Favoreto, M. R. Carvalho, K. N. Galvão, and J. E. P. Santos. 2013. Effects of 1 or 2 treatments with prostaglandin $F_{2 \alpha}$ on subclinical endometritis and fertility in lactating dairy cows inseminated by timed artificial insemination. J. Dairy Sci. 96:6480-6488. http:// dx.doi.org/10.3168/jds.2013-6850.

López-Gatius, F., J. Yániz, and D. Madriles-Helm. 2003. Effects of body condition score and score change on the reproductive performance of dairy cows: A meta-analysis. Theriogenology 59:801812.

Nash, J. G., L. Ball, and J. D. Olson. 1980. Effects on reproductive performance of administration of $\mathrm{GnRH}$ to early postpartum dairy cows. J. Anim. Sci. 50:1017-1021.

Padula, A. M., and K. L. Macmillan. 2002. Reproductive responses of early postpartum dairy cattle to continuous treatment with a $\mathrm{GnRH}$ agonist (deslorelin) for $28 \mathrm{~d}$ to delay the resumption of ovulation. Anim. Reprod. Sci. 70:23-36.

Rhodes, R. C., P. K. Forrest, and R. D. Randel. 1979. The effect of melatonin upon luteinizing hormone in ovariectomized Brahman cows. J. Anim. Sci. 49(Suppl. 1):330. (Abstr.)

Ribeiro, E. S., F. S. Lima, L. F. Greco, R. S. Bisinotto, A. P. A. Monteiro, M. Favoreto, H. Ayres, R. S. Marsola, N. Martinez, W. W. Thatcher, and J. E. P. Santos. 2013. Prevalence of periparturient diseases and impacts on fertility of seasonally calving grazing dairy cows supplemented with concentrate. J. Dairy Sci. 96:5682-5697.

Rutigliano, H. M., F. S. Lima, R. L. A. Cerri, L. F. Greco, J. M. Vilela, V. Magalhães, F. T. Silvestre, W. W. Thatcher, and J. E. P. Santos. 2008. Effects of method of presynchronization and source of selenium on uterine health and reproduction in dairy cows. J. Dairy Sci. 91:3323-3336.
Santos, J. E. P., H. M. Rutigliano, and M. F. Sá Filho. 2009. Risk factors for resumption of postpartum estrous cycles and embryonic survival in lactating dairy cows. Anim. Reprod. Sci. 110:207-221.

Santos, J. E. P., W. W. Thatcher, R. C. Chebel, R. L. A. Cerri, and K. N. Galvão. 2004. The effect of embryonic death rates in cattle on the efficacy of estrus synchronization programs. Anim. Reprod. Sci. 82-83:513-535.

Sartori, R., P. M. Fricke, J. C. Ferreira, O. J. Ginther, and M. C. Wiltbank. 2001. Follicular deviation and acquisition of ovulatory capacity in bovine follicles. Biol. Reprod. 65:1403-1409.

Sheldon. I. M., G. S. Lewis, S. LeBlanc, and R. O. Gilbert. 2006 Defining postpartum uterine disease in cattle. Theriogenology 65:1516-1530.

Skarzynski, D. J., J. J. Jaroszewski, and K. Okuda. 2005. Role of tumor necrosis factor-alpha and nitric oxide in luteolysis in cattle. Domest. Anim. Endocrinol. 29:340-346.

Stevenson, J. S., and E. P. Call. 1988. Fertility of postpartum dairy cows after administration of gonadotropin-releasing hormone and prostaglandin $\mathrm{F}_{2 \alpha}$ : A field trial. J. Dairy Sci. 71:1926-1933.

Thatcher, W. W., and C. J. Wilcox. 1973. Influence of early estrus, ovulation, and insemination on fertility in postpartum Holstein cows. J. Dairy Sci. 56:608-610.

Walsh, R. B., D. F. Kelton, T. F. Duffield, K. E. Leslie, J. S. Walton, and S. J. LeBlanc. 2007. Prevalence and risk factors for postpartum anovulatory condition in dairy cows. J. Dairy Sci. 90:315-324.

Wathes, D. C., Z. Cheng, N. Bourne, V. J. Taylor, M. P. Coffey, and S. Brotherstone. 2007. Differences between primiparous and multiparous dairy cows in the inter-relationships between metabolic traits, milk yield and body condition score in the periparturient period. Domest. Anim. Endocrinol. 33:203-225. 